\title{
Produtividade do milho associado a inoculação com Azospirillum brasilense e diferentes doses de adubação nitrogenada
}

Corn productivity associated with inoculation with Azospirillum brasilense and different doses of nitrogen fertilization

Productividad del maíz asociada a la inoculación con Azospirillum brasilense y diferentes dosis de fertilización nitrogenada

\section{Resumo}

Embora a adubação química nitrogenada seja responsável pelo aumento da produtividade da cultura do milho, sua aplicação também e responsável pelo aumento do custo de produção e por promover uma serie de riscos ambientais. Uma alternativa para esse problema e a fixação biológica de nitrogênio. Este trabalho tem como objetivo a avalição da eficiência da inoculação com Azospirillum brasilense na cultura do milho associada a diferentes doses de adubação nitrogenada em cobertura. O experimento foi realizado na área experimental da UniEvangélica, com os tratamentos: testemunha com $100 \%$ da cobertura; inoculação $+85 \%$ da cobertura; inoculação $+85 \%$ de cobertura e aplicação em cobertura de A. brasilense; inoculação $+100 \%$ da cobertura. Foram avaliados parâmetros morfológicos e a produtividade. Os resultados foram submetidos à análise de variância, e quando ocorreram diferenças significativas, aplicou o teste de médias de Tukey (5\% de probabilidade). A inoculação com A. brasilense e redução de $15 \%$ da adubação nitrogenada em cobertura, apresentou eficiência como promotora de crescimento e desenvolvimento vegetativo, efeito significativo sobre a altura de plantas e na massa verde e seca da inflorescência. A inoculação com A. brasilense não apresentou resultados significativos na manutenção da produtividade frente a redução da adubação nitrogenada, com redução de $21 \%$ na produtividade.

Palavras-chave: Bactérias diazotróficas; Nitrogênio; FBN.

\begin{abstract}
Although chemical nitrogen fertilization is responsible for increasing corn crop productivity, its application is also responsible for increasing production costs and promoting a series of environmental risks. An alternative to this problem is biological nitrogen fixation. This work aims to evaluate the efficiency of inoculation with Azospirillum brasilense in the culture of corn associated with different doses of nitrogen fertilization in cover. The experiment was carried out in the experimental area of UniEvangélica, with the treatments: control with $100 \%$ coverage; inoculation + $85 \%$ of coverage; inoculation $+85 \%$ coverage and application in coverage of A. brasilense; inoculation $+100 \%$ coverage. Morphological parameters and productivity were evaluated. The results were subjected to analysis of variance, and when there were significant differences, the Tukey means test (5\% probability) was applied. The inoculation with $A$. brasilense and a $15 \%$ reduction in nitrogen fertilization in coverage, showed efficiency as a promoter of growth and vegetative development, significant effect on plant height and on the green and dry mass of the inflorescence. The inoculation with A. brasilense did not show significant results in maintaining productivity in the face of reduced nitrogen fertilization, with a $21 \%$ reduction in productivity.
\end{abstract}

Keywords: Diazotrophic bacteria; Nitrogen; FBN. 


\begin{abstract}
Resumen
Si bien la fertilización con nitrógeno químico es responsable de incrementar la productividad del cultivo de maíz, su aplicación también es responsable de incrementar los costos de producción y promover una serie de riesgos ambientales. Una alternativa a este problema es la fijación biológica de nitrógeno. Este trabajo tiene como objetivo evaluar la eficiencia de la inoculación con Azospirillum brasilense en el cultivo de maíz asociado a diferentes dosis de fertilización nitrogenada en cobertura. El experimento se realizó en el área experimental de UniEvangélica, con los tratamientos: control con cobertura del $100 \%$; inoculación $+85 \%$ de cobertura; inoculación $+85 \%$ de cobertura y aplicación en cobertura de A. brasilense; inoculación + cobertura del 100\%. Se evaluaron parámetros morfológicos y productividad. Los resultados se sometieron a análisis de varianza y cuando hubo diferencias significativas se aplicó la prueba de medias de Tukey (5\% de probabilidad). La inoculación con A. brasilense y una reducción del $15 \%$ en la fertilización nitrogenada en cobertura, mostró eficiencia como promotor del crecimiento y desarrollo vegetativo, efecto significativo en la altura de la planta y en la masa verde y seca de la inflorescencia. La inoculación con $A$. brasilense no mostró resultados significativos en el mantenimiento de la productividad frente a la reducción de la fertilización con nitrógeno, con una reducción del $21 \%$ en la productividad.
\end{abstract}

Palabras clave: Bacterias diazotróficas; Nitrógeno; FBN.

\title{
1. Introdução
}

O milho (Zea mays L) é um dos cereais mais importantes do mundo, sendo utilizado na alimentação animal e alimentação humana, e recentemente a Europa e os Estados Unidos têm incentivado seu uso para produção de biocombustíveis, embora muitas comidas típicas no Brasil serem preparadas com o milho, uma pequena parte do milho produzido é destinado a alimentação humana (Menegaldo, 2015).

Por ser uma cultura que requer grande quantidade de nutrientes, principalmente nitrogênio (N), a fonte alternativa de nutrientes dessa cultura traz benefícios agronômicos, ambientais e econômicos, principalmente relacionados ao fornecimento de nutrientes às plantas (Alves, 2020). O N um é um dos nutrientes mais importantes para desenvolvimento da cultura do milho é um dos mais difíceis de manejar, devido à dificuldade das avaliações na sua oferta no solo e os riscos de perdas por evaporação e lixiviação, com isso sua aplicação deve ser feita em doses parceladas nos momentos cruciais da cultura (Cantarella, 2014).

Para o plantio em sequeiro a recomendação de adubação de cobertura é de 60 a $100 \mathrm{~kg} \mathrm{~N}$ ha ${ }^{-1}$, já em plantio irrigado esse valor passa para 120 a $160 \mathrm{~kg} \mathrm{~N} \mathrm{ha}^{-1}$, onde se concentrada maior uso de tecnologia. Dentre as alternativas para a diminuição da adubação nitrogenada na cultura do milho, tem-se utilizado a inoculação com bactérias promotoras de crescimento de plantas e fixação biológica (Oliveira et al., 2018).

As bactérias do gênero Azospirillum, quando associadas às gramíneas, promovem um maior desenvolvimento da cultura. Entre os benefícios paras as plantas estão a sua capacidade de produzir substâncias promotoras de crescimento e a fixação biológica de nitrogênio (FBN). A fixação ocorre através da absorção do $\mathrm{N}_{2}$ e a sua disponibilidade as plantas, a inoculação tem como objetivo otimizar a produção e contribuir para diminuir a utilização de fertilizantes nitrogenados, assim contribuindo na diminuição da emissão de gases de efeito estufas (Oliveira et al., 2018).

Existe uma grande contradição a respeito da eficiência do uso da inoculação de Azospirillum brasilense em sementes de milho, Mumbach et al. (2017), destaca que a inoculação associada a adubação nitrogenada pode aumentar a produtividade e matéria seca do milho, em contrapartida, a redução pela metade das doses de $\mathrm{N}$ em cobertura não afeta o crescimento e rendimento da cultura. Segundo Pandolfo et al. (2015), o uso da inoculação de A. brasilense nas sementes de milho não interfere no aumento de rendimento e não altera a altura e massa da planta e da espiga de milho.

Segundo Hungria (2011), as bactérias endofíticas, que são as bactérias que realizam FBN das gramíneas, como o $A$. brasilense, possuem uma grande diferença em relação as bactérias simbióticas, que realizam FBN nas leguminosas. Essas bactérias excretam somente uma parte do $\mathrm{N}$ fixado para a planta associada, com isso ainda há a necessidade de adubação nitrogenada na cultura, porem com uma menor exigência na quantidade da adubação. 
Com isso, o presente trabalho tem como objetivo a avalição da eficiência da inoculação com A. brasilense na cultura do milho associada a diferentes doses de adubação nitrogenada em cobertura, a fim de avaliar a porcentagem ideal de redução da adubação na cultura do milho.

\section{Metodologia}

O experimento foi conduzido no município Anápolis-GO na área experimental da UniEvangélica, latitude $16^{\circ} 19^{\prime} 36^{\prime \prime}$ S, longitude $48^{\circ} 57^{\prime} 10^{\prime \prime} \mathrm{W}$, altitude $1.017 \mathrm{~m}$, durante o período de novembro a fevereiro de 2019/2020. O clima da região segundo o modelo de Köppen; Geiger é Aw, com precipitação anual média de $1.441 \mathrm{~mm}$.

O solo é classificado como Latossolo Vermelho distrófico, 33\% argila, relevo suave ondulado, apresentando o seguinte perfil de fertilidade segundo a análise de solo (0,0-0,20 m): $\mathrm{pH} \mathrm{CaCl}_{2}=5,2 ; \mathrm{Ca}=2,9 \mathrm{cmol}_{\mathrm{c}} \mathrm{dm}^{-3} ; \mathrm{Mg}=1,3 \mathrm{cmol}_{\mathrm{c}} \mathrm{dm}^{-3}$; $\mathrm{K}=129 \mathrm{mg} \mathrm{dm}^{-3} ; \mathrm{P}(\mathrm{Mehl})=14,3 \mathrm{mg} \mathrm{dm}^{-3} ; \mathrm{MO}: 3,7 \% ; \mathrm{CTC}=9,4 \mathrm{cmol}_{\mathrm{c}} \mathrm{dm}^{-3} \mathrm{e} \mathrm{V}=48,0 \%$. Foi realizada a calagem com 1,5 $\mathrm{t}$ ha $^{-1}$ e aplicação de adubação de base de $400 \mathrm{~kg} \mathrm{ha}^{-1}$ de 05-25-15 no plantio de todos os tratamentos.

O delineamento experimental utilizado foi em blocos inteiramente casualizados, com quatro tratamentos e quatro repetições, a cultura utilizada foi o milho, cultivar LG 3040 PRO2. Cada parcela experimental foi composta de cinco linhas de cultivo espaçadas de $0,65 \mathrm{~m}$ com $20 \mathrm{~m}$ de comprimento. Foi utilizado um inoculante comercial contendo estirpes de $A$. brasilense aplicado no tratamento de sementes (cepas AbV5 e AbV6 [UFPR]), concentração de $2 \times 10^{8} \mathrm{UFC} \mathrm{ml}^{-1}$.

Os tratamentos efetuados foram: T1: não inoculado $+300 \mathrm{~kg} \mathrm{ha}^{-1}$ de ureia $(100 \%)$; T2: inoculado com $A$. brasilense $+255 \mathrm{~kg} \mathrm{ha}^{-1}$ de ureia (85\%); T3: inoculado com A. brasilense+255 kg ha ${ }^{-1}$ de ureia (85\%) e aplicações de $A$. brasilense em cobertura aos 14 e 30 dias após o plantio (DAP); T4: inoculado com A. brasilense+300 kg ha-1 de ureia (100\%).

A aplicação do fertilizante foi feita no momento da semeadura do milho com o auxílio de uma semeadora Tatu PST PLUS, com tração mecanizada. O stand utilizado foi de 4,0 plantas $\mathrm{m}^{-1}$, que equivalem a uma população de aproximadamente 66.600 plantas ha $^{-1}$.

A adubação de cobertura foi realizada no estágio V4, conforme os tratamentos com adubação mineral. Foi realizado o controle de plantas daninhas aos 15 dias após a emergência (DAE) utilizando atrazina $\left(5,0 \mathrm{~L} \mathrm{ha}^{-1}\right)$. Devido à excelente sanidade apresentada pela cultura durante todo o seu desenvolvimento, não foram necessárias aplicações fitossanitárias.

Foram avaliados os seguintes parâmetros: diâmetro do colmo (DC) (mm): na altura de 1,0 cm do solo com um paquímetro; altura de planta (AP) $(\mathrm{cm})$ : a partir do solo até a curvatura da última folha com uma régua graduada em $\mathrm{cm}$. Todas as avaliações foram realizadas a cada 15 dias, totalizando quatro avaliações, sendo encerradas no florescimento pleno da cultura.

$\mathrm{Na}$ fase de grão pastoso foram mensuradas 10 plantas por parcela para determinação do diâmetro de colmo (diâmetro do segundo internódio, a partir da base da planta), altura de plantas (medição do colo até a inserção da folha "bandeira") e da altura de inserção da espiga (medição do colo até a inserção da primeira espiga viável com o colmo).

No ponto de colheita (umidade do grão de $15,5 \%$ ) foi realizada a avaliação de população final de plantas, onde contou-se o número de plantas e o número de espigas por planta em 10 m lineares; comprimento de espiga (CE) (base ao ápice) $(\mathrm{cm})$; diâmetro de espiga (DE) (porção mediana da espiga) (mm); número de fileiras de grãos (NF) e número de grãos por fileira (NGF) e massa de 1.000 grãos (MMG) (g).

A determinação da produtividade foi realizada pelo método proposto pela Emater-MG, conforme especifica Rodrigues et al. (2005), em que procede a contagem do número de plantas em $10 \mathrm{~m}$ lineares e coleta-se três espigas aleatórias para determinação da média do peso dos grãos das três espigas. O procedimento foi repetido dentro do talhão para redução do erro, sendo realizadas quatro repetições por parcela. 
Os resultados foram submetidos à análise de variância (ANOVA), e quando ocorreram diferenças significativas, identificadas pelo teste $\mathrm{F}(\mathrm{P}<0,05)$, se aplicou o teste de médias de Tukey, utilizando-se programa estatístico Sisvar, versão 5.6 (Ferreira, 2014).

\section{Resultados e Discussão}

Considerando as variáveis altura de plantas e diâmetro do colmo, durante o desenvolvimento da cultura houve modificações na dinâmica entre os tratamentos. Sendo assim, pode-se observar que as plantas apresentavam uniformidade na altura, aos 45 DAE, na presença do A. brasilense (Figura 1). Pode-se observar que a diminuição de $15 \%$ de adubação nitrogenada na cultura do milho não interferiu na altura de plantas, tendo a inoculação com A. brasilense como promotor de crescimento.

Figura 1. Análise de altura e diâmetro de colmo em diferentes fases do milho (20; 45 e 60 dias após a emergência - DAE), na presença e ausência de inoculação, aplicações em cobertura com A. brasilense e diferentes doses de nitrogênio, Anápolis, GO.
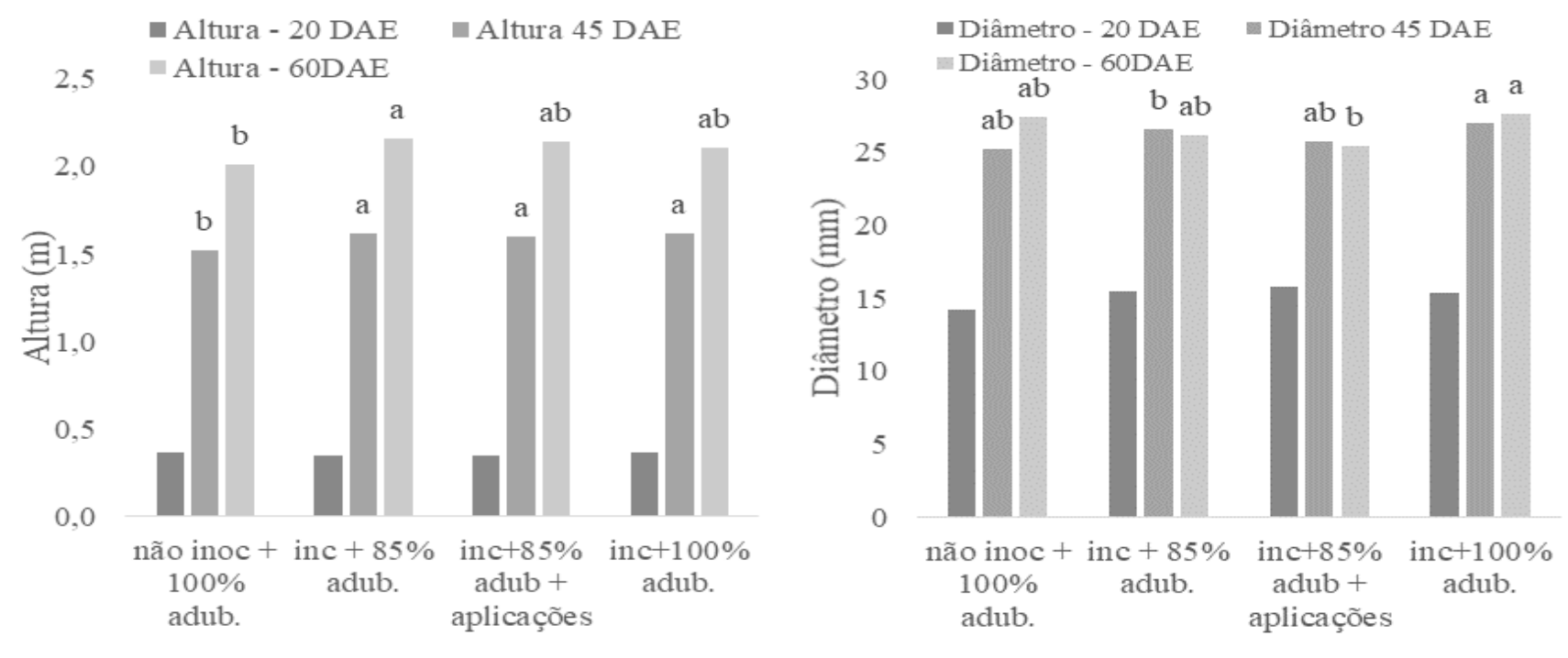

* médias seguidas da mesma letra nas avaliações não diferem entre si pelo teste de Tukey a 5\% de probabilidade. Fonte: Autores.

De acordo com Araújo et al. (2014), a conciliação de adubação nitrogenada e inoculação com A. brasilense, expandiu a produtividade de espigas comerciais de milho verde em até 30\% com uma redução de 15\% na adubação nitrogenada. Para Oliveira et al. (2018), a inoculação de milho com as bactérias A. brasiliense, tanto em plantios onde não há o aporte de fertilizantes nitrogenados, quanto nas que recebem o $\mathrm{N}$ na adubação de cobertura, resulta na produção de substâncias promotoras de crescimento, solubilização de fosfatos e no aumento da resistência da planta ao estresse e a FBN.

Por outro lado, a redução da adubação em cobertura afetou negativamente na variável diâmetro de colmo. Entretanto, para o diâmetro de colmo, o tratamento inoculado em conjunto com 100\% da adubação de cobertura apresentou melhor desempenho do que os demais tratamentos. Diferindo do resultado encontrado por Bassetto Júnior et al. (2020), ao analisar a resposta da presença e ausência de inoculação e diferentes doses de adubação de cobertura na cultura do milho não encontrou diferenças estatísticas entre os tratamentos.

Levando em consideração a variável acúmulo de massa das plantas, pode se observar diferença estatística somente no acúmulo de massa verde das folhas e na inflorescência, sendo que o tratamento com redução de adubação de cobertura e aplicações de A. brasiliense em cobertura foi o que apresentou maior acúmulo de massa nas folhas, seguido pelos demais 
Research, Society and Development, v. 10, n. 2, e42810212711, 2021

(CC BY 4.0) | ISSN 2525-3409 | DOI: http://dx.doi.org10.33448/rsd-v10i2.12711

tratamentos inoculados, mostrando que a inoculação promoveu o acúmulo de massa verde. Já para o acúmulo de massa verde na inflorescência o melhor desempenho foi observado com o uso do A. brasiliense em cobertura e quando se usou a inoculação e adubação completa (Figura 2).

Todas as demais variáveis de massa verde de colmo e massa seca de folhas, colmo e inflorescência não apresentaram diferença estatística. Segundo Durães (2007), plantas com maior teor de matéria seca, podem apresentar maior produtividade. Devido ao maior acúmulo de nutrientes, o que posteriormente pode ser transportado para o grão.

Figura 2. Massa verde (MV - g) e massa seca (MS - g) das plantas de milho na presença e ausência de inoculação, aplicações em cobertura com A. brasilense e diferentes doses de nitrogênio, Anápolis, GO

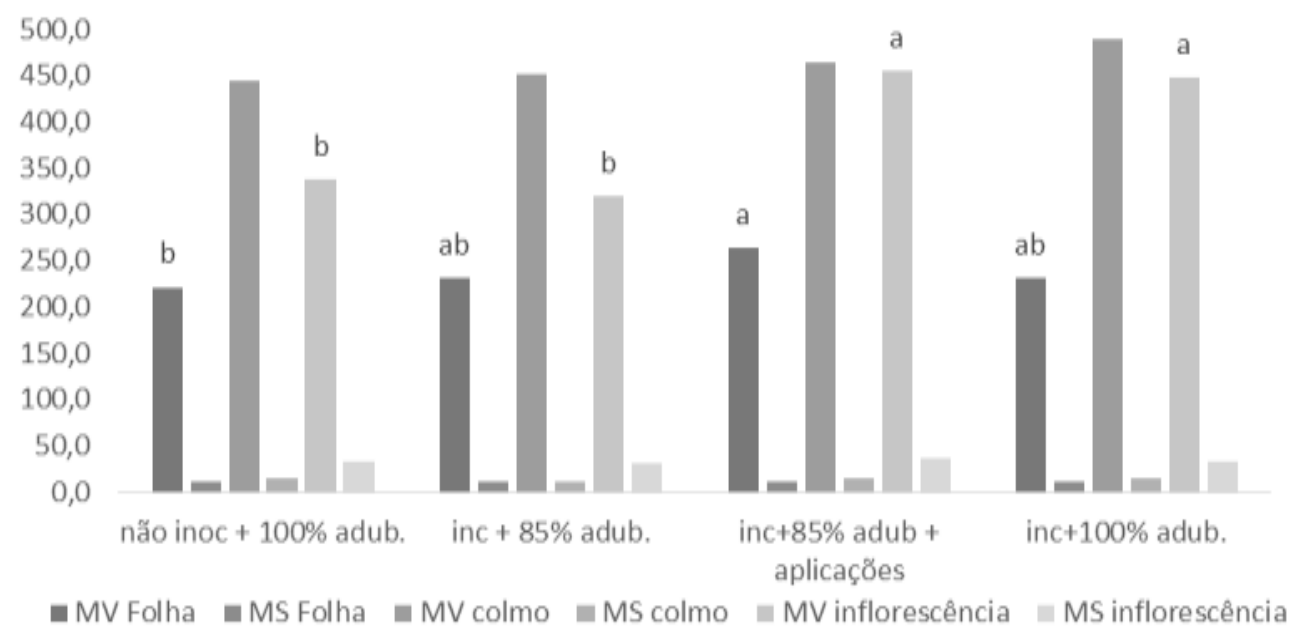

* médias seguidas da mesma letra nas avaliações não diferem entre si pelo teste de Tukey a 5\% de probabilidade. Fonte: Autores.

Observa-se que no tratamento não inoc+100\% adubação, as médias de massa seca são maiores do que o tratamento inoc+85\% adubação, e que o aumento da massa seca das plantas acontece a partir do tratamento inoc+85\% adububação+aplicações de Azospirillum.

Embora apresente resultados no crescimento da parte área de plantas de milho, a inoculação com A. brasilense, quando relacionadas com a produtividade da cultura, não apresenta resultado significativo (Tabela 1). Portanto, o tratamento inoc+ $85 \%$ adubação apresenta uma redução de produtividade de aproximadamente $21 \%$, quando comparado ao tratamento não inoc+100\% adubo, mostrando que a inoculação para FBN não supre a redução de $15 \%$ de adubo. 
Tabela 1. Produtividade da cultura do milho na presença e ausência de inoculação, aplicações em cobertura com A. brasilense e diferentes doses de nitrogênio, sendo comprimento de espiga (CE), diâmetro de espiga (DE), número de fileiras (NF), grão por fileira (GF), massa de mil grãos (MMG), Anápolis, GO.

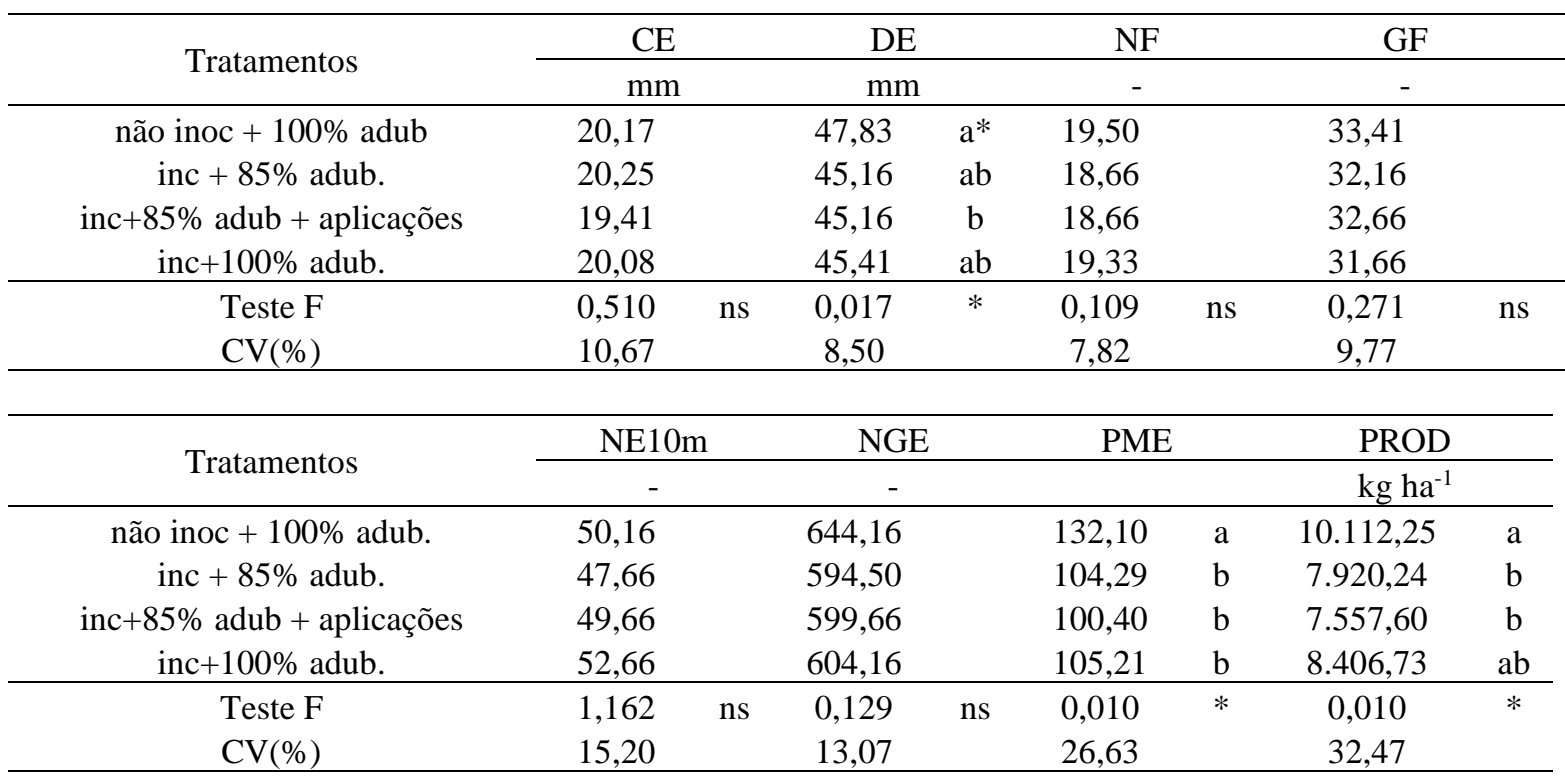

* médias seguidas da mesma letra na coluna não diferem entre si pelo teste de Tukey a 5\% de probabilidade. Fonte: Autores.

Não se constatou diferença estatística nos parâmetros avaliados, como comprimento de espiga (CE), número de fileiras (NF), grão por fileira (GF), número de espigas em $10 \mathrm{~m}$ (NE10M) e números de grão por espigas (NGE). Para os resultados de diâmetro de espiga (DE), massa de mil grãos (MMG) e peso médio de espiga (PME), ocorre diferença estatística, onde o tratamento não inoc $+100 \%$ adubo se destaca dos demais.

Como observado nos resultados apresentados na Tabela 1, o uso de inoculação com A. brasilense não se destacou no rendimento de grãos na cultura do milho, como constatado por Sangoi et al. (2015), independente do sistema de manejo e da dose de adubação aplicadas na cultura, a inoculação com A. brasilense não contribui para o aumento da produtividade da cultura do milho.

As bactérias diazotróficas, por estarem associadas livremente as plantas, na rizosfera ou no interior dos tecidos, podem se tornar vulneráveis ao ambiente, o que pode proporcionar uma menor eficiência (Gyaneshwar et al., 2002); além de que as características do solo (Dobbelaere et al., 2002), temperatura, umidade e a presença de outros microrganismos que podem estar associados baixa resposta da inoculação.

Embora a fixação de $\mathrm{N}$ na inoculação com A. brasilense não tenha demonstrado resultados significativos na produtividade de grãos (Tabela 1), pode se observar uma uniformidade, e até mesmo um incremento, na variável altura de plantas (Figura 1). Essa uniformidade pode estar relacionada à solubilização de nutrientes e produção de fitohormônios por esta espécie microbiana, como por exemplo, auxinas, giberelinas e citocininas, o que demonstra o efeito desta rizobactéria como promotora do crescimento de plantas (Picazevicz, 2017).

Segundo Pandolfo et al. (2015), a tecnologia de inoculação com A. brasilense é uma técnica barata e apresenta um baixo impacto ambiental. Porém, para o aumento da eficiência e assim sua indicação técnica em culturas comerciais, deve ocorrer uma revisão na metodologia aplicada, levando-se em consideração, entre outros fatores, os genótipos utilizados. São necessários novos estudos com novas estirpes e formulações de inoculantes, que possam aumentar a eficiência da FBN, e assim diminuir a dose de fertilizantes químicos utilizados na cultura do milho. 


\section{Conclusão}

Nas condições desse estudo, a inoculação com A. brasilense e redução de $15 \%$ da adubação nitrogenada em cobertura, apresentou eficiência como promotora de crescimento e desenvolvimento vegetativo, efeito significativo sobre a altura de plantas e na massa verde e seca da inflorescência.

A inoculação com $A$. brasilense não apresentou resultados significativos na manutenção da produtividade frente a redução da adubação nitrogenada, com redução de $21 \%$ na produtividade.

Contudo, sugere-se para trabalhos futuros a alterações no número de aplicações em cobertura do Azospirillum brasilense, além de diferentes dosagens de $\mathrm{N}$ em cobertura no milho.

\section{Agradecimentos}

A UniEvangélica pelo apoio técnico e laboratorial concedidos para a realização deste trabalho.

\section{Referências}

Alves, D. K. M. (2020). Desenvolvimento, produtividade e estado nutricional de milho fertirrigado com água residuária de piscicultura e suinocultura diluídas.124p. Dissertação (Mestrado em Ciências Agrárias -Agronomia. Instituto Federal Goiano -Campus Rio Verde -GO, Brasil.

Araújo, R. M., Araújo, A. S. F. D., Nunes, L. A. P. L., \& Figueiredo, M. D. V. B. (2014). Resposta do milho verde à inoculação com Azospirillum brasilense e níveis de nitrogênio. Ciência Rural, 44(9), 1556-1560.

Bassetto Júnior, N. B., Alves, G. H. T., Bellettini, S., \& Bellettini, N. M. T. (2020). Parcelamento de nitrogênio e inoculação das sementes com Azospirillum brasilense na cultura do milho. Brazilian Journal of Development, 6(11), 89544-89663.

Cantarella, A. P. D. H. (2014). Nitrogênio em milho: oferta harmônica. Revista cultivar grandes culturas, 177, 06-08.

Dobbelaere, S., Croonenborghs, A., Thys, A., Ptacek, D., Okon, Y., \& Vanderleyden, J. (2002). Effect of inoculation with wild type Azospirillum brasilense and A. irakense strains on development and nitrogen uptake of spring wheat and grain maize. Biology and Fertility of Soils, 36(4), $284-297$.

Durães, F. O. M. (2006). Limitações fisiológicas do milho nas condições de plantio nas regiões tropicais baixas. In Embrapa Milho e Sorgo-Artigo em anais de congresso (ALICE). In: Congresso Nacional de Milho e Sorgo, 26; Simpósio Brasileiro sobre a lagarta-do-cartucho, Spodoptera frugiperda, 2.; Simpósio sobre Colletotrichum graminicola, 1., 2006, Belo Horizonte, Inovação para sistemas integrados de produção: trabalhos apresentados.[Sete Lagoas]: ABMS, 2006.

Ferreira, D. F. Sisvar: a Guide for its Bootstrap procedures in multiple comparisons. Ciência e agrotecnologia, 2015, 38(2), 109-112. doi.org/10.1590/S141370542014000200001

Gyaneshwar, P., Kumar, G. N., Parekh, L. J., \& Poole, P. S. (2002). Role of soil microorganisms in improving P nutrition of plants. Plant and soil, 245(1), 8393.

Hungria, M. (2011). Inoculação com Azospirillum brasilense: inovação em rendimento a baixo custo. Embrapa Soja-Documentos 325, 36. (INFOTECA-E).

Hungria, M., Campo, R. J., \& MENDES, I. C. (2007). A importância do processo de fixação biológica do nitrogênio para a cultura da soja: componente essencial para a competitividade do produto brasileiro. Embrapa Soja-Documentos 283, 80. (INFOTECA-E).

Menegaldo, J. G. (2011). A importância do milho na vida das pessoas. Embrapa Meio-Norte-Artigo de divulgação na mídia. AGROSOFT Brasil, (INFOTECA-E).

MORAES, G. (2017). Adubação nitrogenada associada à inoculação com Azospirillum brasilense na cultura do milho. Revista Agropecuária Técnica, 38(3), 109-116.

Mumbach, G. L., Kotowski, I. E., Schneider, F. J. A., Mallmann, M. S., Bonfada, E. B., Portela, V. O., \& Kaiser, D. R. (2017). Resposta da inoculação com Azospirillum brasilense nas culturas de trigo e de milho safrinha. Scientia Agraria, 18(2), 97-103.

Oliveira, I. J., Fontes, J. R. A., Pereira, B. F. F., \& Muniz, A. W. (2018). Inoculation with Azospirillum brasiliense increases maize yield. Chemical and Biological Technologies in Agriculture, 5(1), 1-9.

Pandolfo, C. M., Vogt, G. A., Balbinot Júnior, A. A., Gallotti, G. J. M., \& Zoldan, S. R. (2015). Desempenho de milho inoculado com Azospirillum brasiliense associado a doses de nitrogênio em cobertura. Agropecu. Catarin., 27 (3), 94-99.

Rodrigues, V. D. N., Von Pinho, R. G., Paglis, C. M., Bueno Filho, J. S. D. S., \& Brito, A. H. D. (2005). Comparação entre métodos para estimar a produtividade de grãos de milho. Ciência e Agrotecnologia, 29(1), 34-42.

Sangoi, L., Silva, L. M. M. D., Mota, M. R., Panison, F., Schmitt, A., Souza, N. M. D., ... \& Schenatto, D. E. (2015). Desempenho agronômico do milho em razão do tratamento de sementes com Azospirillum sp. e da aplicação de doses de nitrogênio mineral. Revista Brasileira de Ciência do Solo, 39(4), 1141-1150. 
Research, Society and Development, v. 10, n. 2, e42810212711, 2021

(CC BY 4.0) | ISSN 2525-3409 | DOI: http://dx.doi.org10.33448/rsd-v10i2.12711

Picazevicz, A. A., Kusdra, J. F., \& Moreno, A. D. L. (2017). Crescimento do milho em resposta a Azospirillum brasilense, Rhizobium tropici, molibdênio e nitrogênio. Revista Brasileira de Engenharia Agrícola e Ambiental, 21(9), 623-627. 